Gender, Education, and Family Life Courses in East and West Germany: Insights from New Sequence Analysis Techniques 


\title{
Gender, Education, and Family Life Courses in East and West Germany: Insights from New Sequence Analysis Techniques
}

\begin{abstract}
How do men and women's family life courses differ? Are gender differences in family life courses greater at higher or lower educational levels? And how does the intersection of gender, education and family life courses vary across different macro-structural contexts? This paper addresses these questions comparing East and West Germany during the German division (1961-1990). We thereby compare a strong male breadwinner model in a social market economy in West Germany and a universal breadwinner model in a state socialist system in the East. The analysis uses data from the German National Education Panel (NEPS) and employs two new sequence analysis tools: sequence discrepancy analysis and the implicative statistic for analyzing sequences of typical states. These tools enable us to scrutinize the degree, content, and timing of differences in family trajectories between men and women of different educational levels in the two sub-societies. In line with our expectations, family life courses were more de-standardized in the West compared to the East, and this occurred to the same extent for men and women in both contexts. While we find moderate gender differences in family life courses across all educational groups in the strong male breadwinner context in West Germany, for East Germany gender differences were significant among the medium and lower educated, but not among the highly educated. These findings underline the fact that the intersection of gender and education for family life courses is highly context-specific. They further suggest that different patterns of assortative mating play a key role for gender differences in family life courses. We demonstrate the added value of sequence discrepancy analysis and the implicative statistic to illuminate differences in longitudinal life courses between men and women or other social groups.
\end{abstract}

KEY WORDS: family life course, gender, education, East/West Germany, sequence discrepancy analysis, implicative statistic for sequences of typical states analysis. 


\section{Introduction}

The intersection of gender and education for stratifying family and employment life courses has recently received increasing attention (Cooke, 2011; Esping-Andersen, 2009; Evertsson et al., 2009). In particular, scholars are debating whether high gender differences in life courses go along with lower differences by education and other concepts of social status and vice versa. Unlike classic concepts of social class or social status that capture a relational type of inequality, education refers to inequality in an attributional sense (Goldthorpe, 2012:204). Education is thus logged within individuals themselves and strongly related to individual income, whereas social class and social status are inherent in relations between (groups of) individuals. To date, many studies have addressed the profound impact of education on family life courses, primarily for women. In addition, there are several well-documented gender differences in family life courses in developed societies: compared to women, on average men marry and enter parenthood later, and have lower probabilities to live with their children as single parents after separation (e.g. Huinink \& Mayer, 1995; Huinink, 2000). Yet, few studies have addressed gender differences in family trajectories directly and we know little about how such gender differences vary by educational level. This is important to shed light on the intersection of gender and education for family life courses.

How gender and education play out for family life courses will depend on social policies, and other macro-structural conditions. Social policies and broader welfare state characteristics set incentives and constraints for individuals to marry or cohabit, have children or not, remain single or divorce. Often these incentives and constraints are genderspecific and affect individuals differently depending on their educational degrees. Arguing for a differential life course sociology, Mayer (2005) points to the pitfalls of comparing broad categories of welfare state regimes and lays out the added value of targeted country case studies. To disentangle the linkages between institutional configurations and life course outcomes it is most conducive to disaggregate broad regimes into distinct policy fields and match them to specific life course outcomes.

Our study is placed within this paradigm. The life course outcomes of interest are longitudinal family trajectories that combine union formation and dissolution as well as fertility from ages 18 to 40. This is important to assess gender differences comprehensively, because men and women might be very similar in one marker, e.g. completed fertility, but differ widely in others, for instance the timing of births or total number of relationships. We use the historically unique case study of divided Germany into the communist German Democratic Republic (GDR) and the social market economy 
of the Federal Republic of Germany (FRG). The analysis focuses on the cohorts born between 1944 and 1955, who experienced their active family formation phase (ages 18 to 40) precisely from 1961 to 1990 in divided sub-societies. The GDR promoted a classless egalitarian society, a universal breadwinner model, and pro-natalist family policies. Moreover, the access to higher education was strongly regulated by the state. In contrast, the FRG represented a fairly unequal stratification system that was strongly transmitted through education combined with pro-traditionalist family policies favouring the malebreadwinner model (Cooke, 2011; Engelhardt et al., 2002; Huinink et al., 1995). The German sub-societies therefore are a particularly good case for examining gender differences in family trajectories for different educational levels in similar language and cultural contexts, but vastly different incentives and opportunity structures on the macro level.

We thus address two research questions in this study. First, we consider, whether the de-standardization of family life courses was larger for men and women in East or in West Germany (research question 1). De-standardization of family life courses refers to the extent to which the timing, sequencing, and order of unions and childbirths varies across the population (Brückner and Mayer, 2005). The degree of de-standardization is informative about the regulative power of welfare institutions, including education systems and family policies, as well as the strength of social norms about the "right" timing for certain life course transitions, including marriage and parenthood (Neugarten et al., 1965; Settersten \& Hagestad, 1996; Settersten \& Mayer, 1997). We are interested in whether this institutional and normative power standardizes individuals' family trajectories to varying degrees depending on their gender and education in the two contexts.

Secondly, we directly assess whether gender differences in longitudinal family life courses vary across educational groups, and whether these associations differ between the GDR and the FRG (research question 2). To address that question, we analyze both the quantitative degree of gender difference in family trajectories, and explore its qualitative content in terms of the prevalence and timing of specific family states for men and women for different educational levels.

The analyses use data from the German National Education Panel (NEPS) and employ two newly developed tools for analysing state sequences (Studer et al., 2011; Studer, 2012) that overcome weaknesses of previously available sequence analysis techniques: sequence discrepancy analysis and the analysis of sequences of typical states based on implicative statistics. Sequence discrepancy analysis allows us to directly study the relationship between the family trajectories and covariates, such as gender and 
education, and to measure its strength without any prior clustering (cf. Abbott \& Tsay, 2000). Avoiding prior clustering circumvents implicit and often substantively problematic assumptions (Studer, 2013). In addition, the implicative statistic provides us with a tool to pin down salient qualitative differences between the family trajectories, as well as the timing when family life courses start to significantly diverge between men and women.

We seek to contribute to the literature on the subject (??) both substantively and methodologically. Substantively, we highlight that gender differences in family life courses at different educational levels are highly specific to different country contexts. This underlines the importance of institutions and macro-structural contexts in shaping associations between gender, education, and family life courses. While we find moderate gender differences in family life courses across all educational groups in West Germany, in East Germany gender differences are sizeable among the medium and lower educated but there are no gender differences between highly educated men and women's family trajectories. The findings are consistent with a homogenizing effect of longer educational participation on men and women's family life courses and suggest that country-specific patterns of assortative mating play a key role for gender differences in family trajectories. Methodologically, we demonstrate how the recently developed tools of sequence discrepancy analysis and the sequence implicative statistic add to previous sequence analysis techniques in two respects: 1) by directly assessing the degree to which covariates account for differences between sequences, and 2) by precisely locating the nature and timing when significant differences between men and women's family trajectories occur.

\section{Background and Theory}

\subsection{Gender, education, and the de-standardization of family life courses}

Family demographers routinely include education as a determinant of family outcomes, including marital and non-marital fertility, cohabitation, marriage, divorce or mothers' return to employment after childbirth (e.g. Carlson et al., 2004; Carlson \& England, 2011; Kreyenfeld, 2010). In these studies, outcomes tend to be conceptualized as point in time and trend outcomes, e.g. fertility rates, probabilities of separation, or the duration until an event occurs (Abbott, 2005). Empirical evidence shows that the educational gradient in family events varies greatly across countries, supporting that welfare state institutions and macro-structural contexts profoundly shape the education gender - family nexus (Cooke, 2011; Orloff, 2009). For instance, women's child-bearing in cohabitation is associated with lower education in most European countries, but to very 
different degrees (Perelli-Harris et al., 2010). In a comparison of 17 countries, Härkönen \& Dronkers (2006) report high divorce rates among highly educated women in some countries (e.g. France), no impact of education in others (e.g. West Germany), but lower divorce rates among the highly educated in countries such as Sweden and the United States. Similarly, high education is associated with upward mobility for mothers after child birth in Germany and Sweden, but not in the United States (Aisenbrey et al., 2009).

Most of these studies include women only. As a result we know much less about men's family life courses or about gender differences in the relationship between education and family trajectories. A few recent studies directly address differential effects of education for men and women's family life courses. Overall research on the relationship between education and fertility has produced mixed findings (Balbo et al., 2013; Huinink, 2000). For Norway, high education has been found to reduce fertility for women but increase fertility for men (Kravdal \& Rindfuss, 2008), which leads to greater gender differences in fertility for the highly educated compared to the lower educated.

In addition to examining point in time and trend outcomes, a central concern of family research from a life course perspective is to assess the degree of difference, i.e. the de-standardization (see Brückner and Mayer, 2005) of longitudinal family trajectories as process outcomes (Abbott, 2005). The de-standardization of family life courses is then compared across countries and cohorts and interpreted as an indicator of the extent to which institutional and normative forces regulate and homogenize this life course process. Previous research on the de-standardization of family trajectories reports considerable variation across historical time and across countries (Aassve et al., 2007; Billari, 2001; Bras et al., 2010; Cook \& Furstenberg, 2002; Elzinga \& Liefbroer, 2007; Huinink, 2011). For instance, several studies show that family life courses were highly standardized under the regulative communist regimes in Eastern Europe compared to most Western countries but became much more de-standardized during the system transformation in the postcommunist societies in the 1990s (Elzinga \& Liefbroer, 2007; Fasang, 2014).

Similar to research on point in time family outcomes, most empirical studies on longitudinal family trajectories acknowledge the gender specificity of this process by exclusively focusing on women (Aassve et al., 2007; Elzinga \& Liefbroer, 2007; Fasang, 2014). To date, only Widmer and Ritschard (2009) directly address gender differences in the de-standardization of family trajectories in Switzerland. They find larger gender differences in the de-standardization of occupational trajectories than of family trajectories. To our knowledge, there are no studies that directly examine differences in de- 
standardization of family life courses by education, neither between genders nor across contexts.

\subsection{Education and gender differences in family life courses}

The literature prominently distinguishes between 1) educational level and 2) educational participation (or institutional) effects on family trajectories (Blossfeld 1995; Blossfeld \& Huinink, 1991; Huinink, 2000). In the context of our study, educational level and educational participation effects are relevant to the extent that they help us understand gender differences in family life courses. Most studies on these effects focus on women's family events, primarily marriage and motherhood (e.g. Blossfeld \& Huinink 1991). Yet, educational level and educational participation effects have been shown to operate in gender-specific ways and can thereby contribute to gender differences in family life courses (e.g. Brüderl \& Diekmann, 1994). In addition, country-specific patterns of 3) assortative mating likely play an important role for gender differences in family life courses for different educational groups.

1) The educational level argument holds that education primarily affects family trajectories through returns to human capital investment (Becker, 1981; Blossfeld \& Huinink 1991). Educational levels and associated human capital operate in gender-specific ways. First, the opportunity costs of having children increase with higher education for women but not for men. Secondly, the capacity to attract partners and provide for children increases with education for men, but this does not apply to women to the same extent (Blossfeld \& Timm, 2003; Mickelson, 2003). As a result highly educated women face high opportunity cost of children and are more independent from husbands' earnings. Therefore they will delay partnering and parenthood, possibly indefinitely. This delay effect is expected to hold while they are in educational system, but also after they have completed their education, established careers, and benefit from the returns to human capital. In contrast, for lower educated women who lack rewarding job options, opportunity costs of having children are lower. For them marriage and motherhood are more attractive routes early on.

On the contrary, for men, human capital increases the capacity to provide for a family and attract partners but does not increase the opportunity costs of children as long as women are primarily responsible for child care. Highly educated men might therefore delay family formation until the completion of education, but quickly enter committed partnerships and fatherhood once they begin to collect the returns to high human capital (Brüderl \& Diekmann, 1994). Lower educated men, in turn, lack the resources to attract 
partners and provide for a family and therefore will delay or forego starting a family even if they are no longer in education. These effects will be stronger and thus generate larger gender differences in family life particularly for the lowest and highest educated. Furthermore, countries that strongly favour the male breadwinner model would reinforce gender-specific educational level effects more than gender egalitarian ones.

2) The educational participation effect, also termed institutional effect (Huinink, 2000) assumes that practical constraints during educational participation and norms about the proper sequencing of life course events are the decisive links between education and family trajectories - and not human capital (Blossfeld \& Huinink, 1991; Hoem, 1986; Huinink, 2000). Such constraints and norms will lead to a postponement of committed partnerships and parenthood until the completion of education. Accordingly, we would expect higher gender differences in family life courses, if gender-specific norms exist about the "right" timing of education and family life events and if practical constraints to combine education and starting a family vary for men and women. In terms of normative expectations, in most Western societies the completion of education is perceived as a necessary pre-requisite for starting a family for both men and women (Settersten \& Mayer, 1997). Regarding practical constraints, education places high demands on time and usually goes along with financial dependence on parents, which are incompatible with parenting roles. Especially in country contexts with strong male breadwinner expectations and weak child-care infrastructures (such as FRG), time constraints will be particularly relevant for women who try to combine motherhood with education (Beck-Gernsheim, 1988). In more gender egalitarian contexts that ease compatibility problems of education and motherhood (GDR), women will be more inclined to start forming a family while still participating in education (Blossfeld, 2014). In contrast, financial constraints are likely more relevant for men to postpone family formation until they completed education and accumulated sufficient resources to meet the "marriage bar", particularly in male breadwinner environments (Blossfeld \& Nuthmann, 1989; McLanahan \& Percheski, 2008; Rindfuss et al., 1988).

3) Assortative mating and the distribution of educational degrees among men and women are additional important links between education and gender differences in family life courses (Blossfeld \& Timm, 2003; Kreyenfeld, 2004) ${ }^{1}$. Family trajectories are located on the individual level, but many relevant decisions on union formation, union dissolution

\footnotetext{
${ }^{1}$ Because we lack information on same sex couples for our study cohorts and the theoretical ideas we refer to were developed for heterosexual couples, all considerations on couple dynamics are limited to opposite sex couples.
} 
and parenthood take place within couples. As a result, men and women who partner with each other will tend to have similar family life courses. Consider a thought experiment in which educational degrees are equally distributed for men and women and assortative mating is complete, i.e. women only partner with men of the same educational degree and vice versa. If family life courses are specific to educational levels, this could cancel gender differences in family trajectories because partnered men and women with the same educational level follow very similar family trajectories. There could still be large differences in family formation between educational groups. Educational institutions function as mating markets that can additionally foster educational homogamy and gender similarity in family life courses through joint participation effects particularly on highly educated men and women (Blossfeld \& Timm, 2003). In contrast, when educational homogamy is weaker, family trajectories of partners with different educational degrees might be very similar. In this case, men and women with the same educational level, who have partners of different educational degrees, could be more different. For example, if highly educated men tend to partner with lower educated women, they could have similar family trajectories, while large gender differences persist between highly educated men and women's family life courses.

Moreover, longer educational participation can result in unintended level effects due to norms of educational homogamy in couples. For example, higher educated women might unintentionally have lower chances on the marriage market once they have completed their education if they prefer not to marry downward and men prefer not to marry upward (Blossfeld \& Huinink, 1991; Oppenheimer, 1988). As a result, one could expect an acceleration effect of family formation for highly educated women once their education has been completed. At this point they are already relatively old and increasingly under pressure of biological constrains to motherhood and societal norms about the right timing for parenthood (Blossfeld \& Huinink, 1991).

To summarize, according to the educational level hypothesis, the gender-specific link between human capital and the opportunity cost of children will lead to long-term gender differences in family life courses for all educational levels. Highly educated men and lower educated women would be most likely to form large families. Higher educated women and lower educated men will delay and forego marriage and parenting, albeit for different reasons. We would therefore expect high gender differences in family formation particularly for the lowest and highest educated, because they differ most in the genderspecific link between human capital and family events, even after the completion of 
education. In contrast, the educational participation hypothesis assumes that men and women with higher education will delay family formation due to similar normative expectations and gender-specific practical constraints of combining education and starting a family. We would therefore assume that remaining in education longer will homogenize men and women's life courses and reduce gender differences in family trajectories particularly for the highly educated. Finally, considerations about assortative mating suggest that gender differences in family life courses will be lowest for those educational groups for which assortative mating is strongest. Because educational institutions function as mating markets, individuals who stay in them longer will have higher probabilities to meet and mate with partners of similar educational degrees. We could therefore assume that assortative mating will tend to reinforce educational participation effects by homogenizing family life courses particularly for the highest educated men and women.

\section{Macro-structural contexts in the GDR and the FRG}

Between 1961 and 1990 Germany was divided into two sub-societies, the GDR and the FRG. In selecting the GDR and the FRG, we aim at a case comparison with particularly strong differences in the macro-structural contexts during the prime family formation age, while at the same time constituting very similar language and cultural backgrounds (Kreyenfeld, 2004). Neither the FRG nor the GDR were static over time, but changes were relatively small compared to large differences in social policies and macro-structural contexts between the two sub-societies. In this study we focus on 12 births cohorts (194455, see below) who experienced their onset of family formation in the early years of the GDR and largely completed the active family formation phase before the reunification.

\subsection{Education systems and educational homogamy}

Despite its communist ideology, the GDR was neither a classless nor an egalitarian society (Solga, 2006). Yet in comparison with the FRG, East Germany was more homogenous in terms of education, employment, and income, due to strong state regulation on education, central planning of wages and relatively generous state provision for basic income and housing (Mayer, 2006). In both sub-societies education was strongly regulated with an elaborate vocational training system. However, admission to higher education was more restricted and centrally controlled by the state in the GDR (Blossfeld et al., 2015). Thus, only a small, selected quota of each GDR generation made it to the university level. In the FRG, everyone who completed the Gymnasium could in principle continue to university, which resulted in higher selectivity by parental background compared with the 
GDR. For the cohorts we focus on, tertiary education was also not yet wide spread in West Germany, because the educational expansion only took effect strongly for the cohorts born 1964-1970 (Blossfeld et al., 2015:152).

Overall, in the FRG, educational credentials were more unequally distributed and played a key role in the allocation of persons to positions in the more meritocratic social market economy. For our study cohorts, according to the NEPS data, around $45 \%$ of men and women held only a primary educational degree, followed by $27 \%$ secondary degrees for men and $36 \%$ of secondary degrees for women (see Table 1, detailed description of data below). The proportion of men with only primary education thus was relatively large among West German men. They often had limited prospects on the marriage market as they struggled to fulfil male breadwinner expectations. Access to tertiary education in West Germany was gendered with $30 \%$ of men but only $18 \%$ of women holding a university or equivalent degree for our study cohorts.

In contrast, in East Germany only $21 \%$ of men and $17 \%$ of women held a primary degree, followed by $51 \%$ of men and $60 \%$ of women with secondary degrees, usually a low degree of general schooling combined with vocational training (Table 1). Access to higher education was equally restricted to about a third of the population, but it was less gendered in East Germany with $28 \%$ of men and $23 \%$ of women holding tertiary degrees. These numbers correspond with data from other sources with slight deviations in proportions and analysis cohorts (e.g. Kreyenfeld, 2004:296).

The importance of educational homogamy for the relationship between education and fertility is well-documented (Kreyenfeld, 2002). For this study we lack direct information on a partner's characteristics and educational homogamy, which is not available for our study cohorts in East and West Germany in combination with detailed longitudinal family formation trajectories until age 40. Nevertheless, it is important to consider how known patterns of gender-specific educational attainment and educational homogamy in the two sub-societies could contribute to gender differences in family trajectories across educational groups.

In the conservative male breadwinner state of West Germany, educational homogamy was widespread, followed by couples in which men held higher educational degrees than their wives (Blossfeld \& Timm 2003; Kreyenfeld, 2002; Wirth, 2000). Blossfeld and Timm (2003:25) report that only around 5\% of West German husbands married educationally upward for our study cohorts. For both sub-societies studies find the highest educational homogamy among the highly educated (Blossfeld \& Timm, 2003; Solga, 1995). Institutions of higher education function as mating markets and thus increase 
the likelihood for men and women who remain in them for longer durations to meet and mate. However, in the West a more unequal distribution of higher education among men and women left a larger number of highly educated men without potential highly educated female partners. Given norms of educational homogamy, highly educated men were therefore more likely to marry downward than in the East. In contrast, in the GDR, women were almost equally likely to be admitted to the university as men for our study cohorts. This resulted in strong homogamy among the highly educated, which might equalize their family trajectories. However, due to a greater relative share of highly educated women seeking to find partners, highly educated East German women were also more likely to marry lower and medium educated men compared to the West (Bertram, 1992; Solga, 1995). Based on homogamy considerations, we would therefore expect highly educated men and women to have the most similar family formation trajectories in both subsocieties. Due to stronger homogamy among the highly educated in the East, men and women's family trajectories could be even more similar than for the highly educated in the West.

\subsection{Family policies}

Whereas the family ideology in the GDR was primarily pro-natalist, it was foremost pro-traditional in the FRG (Engelhardt et al., 2002; Rosenfeld et al., 2004). Family policies in the GDR conditioned access to state-controlled resources on marriage and parenthood (see Kreyenfeld, 2004 for details) - including housing, generous loans from the state, and public holiday camps. These generous financial incentives were coupled with normative pressure to have children in the early $20 \mathrm{ies}$ that possibly undermined the normative expectation to complete education before marrying and having children. Further generous incentives for marriage and parenthood lowered the opportunity costs of these family moves for all educational groups (Brüderl \& Diekmann, 1994). The GDR was strongly committed to actively integrating women into the labour market (Trappe, 1995 and 1996). Public child-care widely enabled mothers' employment, which was further promoted by an "ideology that glorified the working woman" (Kreyenfeld 2004: 279) and facilitated many open positions in a centrally planned economy in which unemployment practically did not exist. As a result, female labour market participation rates were consistently high, around 90\%, also for mothers (Huinink et al., 1995). Overall in the East, gender equality on the labor market reached unprecedented levels with a lower gender wage gap and no reported motherhood penalty in wages (Budig et al. 2012; Rosenfeld et al., 2004; Trappe \& Rosenfeld, 1998). Pro-natalist policies eased practical compatibility 
problems of parenthood during education in the GDR. Therefore financial dependence and uncertainties about future life course prospects were much less pronounced compared to the FRG given the expectation of secure life-time employment and overall fewer options to choose from in life (see Huinink, 1995 and 2000).

In contrast, in the FRG, social policies comprehensively set strong incentives for a specialized male breadwinner-female caregiver household division of labour and the financial dependence of women on men (Brückner, 2004; Cooke, 2011). The tax system imposed the most severe penalties on working wives in a comparison of 14 rich democracies (Sainsbury, 1999). Combined with a lack of public childcare, particularly for children under the age of three, this strongly discouraged employment of a second earner (Aisenbrey et al., 2009, Cooke \& Baxter, 2010). In addition, the normative climate in the FRG regarded mother's employment as harmful for small children (Treas \& Widmer, 2000). As a consequence, female labour market participation was only around $50 \%$, of which much was part-time.

3.3 Previous findings on education and men and women's family life courses in the FRG and the GDR

Previous studies show markedly different fertility and union trajectories for women in the GDR and the FRG. Total period fertility rates initially peaked at 2.5 in the mid1960s in both sub-societies, followed by a drop to a stable level of about 1.5 in the late 1960s in the FRG. In contrast, in the GDR, period fertility increased back to 2.0 in the late 1970s, declined sharply during the first period after reunification and increased slowly later on to similar levels as in the FRG (Goldstein \& Kreyenfeld, 2011; Kreyenfeld, 2004). Fertility among West German women was not only lower, but also occurred at later ages across all educational groups in the FRG (Kreyenfeld, 2004:297). Among highly educated women, differences between the sub-societies were most striking. In the FRG, the median age of first birth was 32 with around $40 \%$ childlessness at age 35 . In contrast, the median age in the GDR was only 27 and childlessness at age 35 was much lower at around 10\% (Kreyenfeld, 2004).

In the initial phase of the GDR, marriage was more widespread than in the FRG (Fasang, 2014). Both men and women married at younger ages in a shorter demographically dense phase in early adulthood than in the FRG (Keiser, 1992). Data from the German Life History Study (Mayer, 2008) further suggests that women's longitudinal family trajectories from ages 15 to 33 were more standardized with early marriage and parenthood in the GDR than in the FRG (Fasang, 2014). Divorce rates were also higher in 
the GDR compared to the FRG (Wagner, 1997), were cheaper and easier divorce procedures were available. Therefore, despite the high prevalence of marriage, rates of single motherhood were also higher in the GDR where pro-natalist family policies provided generous support for single mothers as well.

Findings on participation and level effects of education on family events for the FRG are mixed. Several studies support a polarization of highly educated women into either early marriage and parenthood coupled with economic inactivity, or foregoing marriage and motherhood in favour of establishing a career (Brüderl, 2004; Fasang, 2014). Whereas some authors show no independent effect of educational level after controlling for the delaying impact of educational participation on marriage and parenthood (Blossfeld \& Huinink, 1991), others do find an independent effect of higher educational degrees on women's family life courses in West Germany (Brüderl \& Diekmann, 1994). Overall, we know comparatively little about men's family trajectories in the GDR and the FRG, since data on men's fertility is sparser than it is for women (Kreyenfeld et al., 2011). Further, to date, no study has examined gender differences in longitudinal family trajectories in the GDR and the FRG.

\section{Research questions and hypotheses}

First, we consider whether the variability, i.e. the de-standardization, of family life courses was larger for men and women in East or in West Germany (research question 1). Because state regulation was high and policies aimed at equalizing male and female life courses across all life domains, we hypothesize that family life courses will be equally standardized for men and women on the GDR. In contrast, the male breadwinner policies in the FRG will lead to more de-standardized family life courses for both genders (hypothesis 1). Men reach the "marriage bar" for fulfilling the male breadwinner role at varying ages and women polarize into a pattern of traditional early family life course or possibly infinitely delayed family formation as they struggle to reconcile employment and motherhood. Comparing educational groups, we would expect a higher standardization among highly educated men and women compared with lower educated individuals in both sub-societies, due to a homogenizing effect of participating in educational institutions on life courses (hypotheses 2).

Secondly, we ask whether gender differences in family trajectories vary across educational groups in different ways in East and West Germany (research question 2). On the one hand, in the FRG pro-traditionalist family policies possibly reinforce gender differences in all life course dimensions, including the family domain irrespective of 
education. In contrast, in the GDR education was more equally distributed across genders and played a smaller role in the allocation of resources. In addition pro-natalist family policies aimed to facilitate parenthood during educational participation for men and women. This would suggest smaller gender differences in family life courses for all educational groups in the GDR compared to larger gender differences for all educational groups in the FRG (hypothesis 3).

On the other hand, if educational homogamy plays a crucial role in gender differences in family trajectories, we would assume lower gender differences in family life courses for those educational groups in which homogamy is strongest (hypothesis 4). This would imply the lowest gender differences in family trajectories for the highly educated in both sub-societies. An equalizing impact of homogamy on highly educated men and women's family life courses could be reinforced by an educational participation effect of the longer period both partners spent in higher education. Because higher education was more equally distributed among men and women in the East, homogamy was even higher among the highly educated compared to the West. This could lead to even lower gender differences in family life courses for the highly educated in the East compared to the West.

\section{Data and methods}

We use retrospective data of the Starting Cohort Six of the National Educational Panel Study (NEPS) (Blossfeld et al., 2011) for individuals born in East and West Germany ( $\mathrm{N}=423$ and $\mathrm{N}=1,778$ respectively) between 1944 and 1955. These cohorts experienced their active family formation from ages 18 to 40 between 1962 and 1990, precisely in divided German sub-societies. This enables us to assume largely completed fertility and capture most family events also for the highly educated, which has not been possible in previous research that uses data censored at younger ages (Huinink, 1995; Kreyenfeld, 2004). Those born in the 1950s did experience the end of the family trajectory after the reunification, but everyone in our sample was at least 35 years old at the time of reunification. This is well after the onset of family formation given a median age of first birth of 22 for East German women (mean=22.8), 24 for East German men (mean=24.7), of 25 for West German women (mean=24.8) and 28 for West German men (mean=27.7) in our sample.

To ensure a rigorous comparison of the GDR and the FRG, we only included respondents in the sub-society samples, who were born in the respective region and were still living there at the time of the interview in 2009/2010. We excluded foreign-born individuals, respondents who migrated between East and West, and individuals living in 
Berlin. This was necessary because the NEPS did not distinguish between the former East and West regions of Berlin at the time of the interview in 2009/2010 and thus the assignment to either the East or West would have been ambiguous.

Family trajectories from ages 18 to 40 were operationalized as sequences of monthly intervals combining union formation and dissolution (single, cohabiting, or married) and fertility (with or without child/children) in joint family states (Figures 1 and $2)^{2}$. Being single is defined as not being in a cohabiting relationship and thus includes persons who were never married as well as divorcees and separated individuals. Single parents are operationalized as adults who are not in a relationship but have at least one biological child, irrespective whether they live with the child or not. The category of single parents therefore includes resident and non-resident single parents. Only biological children are included. The percentage of reported adopted and foster children is very low (below $1 \%$ in each sub-society) and legislation and practice of adoption and foster parenting differed substantially in East and West Germany.

Note that there might be some underreporting of male fertility, which is typical for survey data (Kreyenfeld et al., 2011), but this is unlikely to distort the comparison between the two sub-societies. Regarding possible misreporting of relationship status the NEPS Starting Cohort Six's team went through great length to minimize recall error by combining modularized self-reports and event history calendars (Drasch \& Matthes, $2013)^{3}$. Despite the many advantages of this data to address our research questions, we lack information directly collected from the respondents' partners. For our study cohorts there is no data source that contains reliable information on both partners in the FRG and the GDR. We are thus unable to directly observe educational homogamy, but can relate our findings to expectations derived from known patterns of assortative mating in the two German subsocieties (Blossfeld \& Timm, 2003) (see hypothesis 4 above).

\footnotetext{
${ }^{2}$ Education partly occurs parallel to family trajectories and the two processes are tightly intertwined. In our analyses, we stratified the sample according to the highest educational degree completed, thus educational completion occurs during the family trajectory for the higher educated. As a robustness check, we tested a different specification of both family sequences and education. First, we defined the sequences as the first 16 years after completing the highest educational degree to ensure that education is temporally antecedent to the family trajectories. Secondly, we used parental education (number of years in education for the highest educated parent) and followed individuals' family trajectories from ages 15 to 40 . Our main findings (see below) hold for all three specifications (results available from authors).

${ }^{3}$ Building on insights from cognitive psychology, this technique combines event history calendars with an automated data revision tool that detects gaps, overlapping events and inconsistencies during the interviews and prompts the interviewer to immediately ask for clarification. It is fairly safe to assume that recall error is not a major issue in the NEPS data for information on objective and major life events, such as marriage, birth of children, or divorce. Recall error regarding short periods of cohabitation and early separations might be more serious and could lead to an underreporting of these events. However, this recall error is unlikely to systematically vary between East and West Germany to an extent that it would fundamentally invalidate our findings. Nonetheless, the likely underreporting of short periods of cohabitation and early separations in both sub-societies should be kept in mind when interpreting our findings.
} 
- Table 1 about here -

Education was measured as the highest educational degree obtained derived from the CASMIN classification. We collapsed the original categories in three groups corresponding to low education (1b and 1c: Hauptschulabschlu $\beta$ and Volksschulabschluß), medium education (2a, 2b, and 2c_gen/2c_voc: Realschulabschluß, Fachhochschulreife, and Hochschulreife), and high education (3a and 3b: Fachhochschule, Ingenieurschule, and Universitätsabschluß). Table 1 shows the distribution of education by gender and subsociety. As noted above (section 3.1), education is overall more unequally distributed in the FRG compared to the GDR and women in the GDR had more access to higher education.

\subsection{Methods}

Our research questions require determining whether the relationship between gender, education, and family trajectories is significant in different contexts (FRG vs. GDR) and measuring the strength of this association ${ }^{4}$. In the sequence analysis framework, this is usually done by first clustering the sequences and then assessing the strength of the relationship with methods for categorical data analysis, such as the chi-square test or Cramer's $v$ (e.g. see the review by Abbott \& Tsay, 2000). This strategy is based on several questionable implicit assumptions (Studer, 2013), including that the intra-cluster variability can be safely ignored. This is the case if well-defined models of trajectories generated the observed sequences and if these models were truly recovered by the cluster analysis. However, this assumption is debatable from a sociological point of view. Following the life course paradigm, one can assume that individuals are subject to various influences and constraints, which - each in their own way - contribute to the resulting trajectory (or part of it). This is a long way from the search for clearly defined models of trajectories in homogeneous clusters. We do not know whether such an assumption would hold or not in our case. Moreover, this is not a central issue in our research questions. Instead, we are interested in whether we can observe systematic difference in family trajectories between men and women in different contexts.

The discrepancy analysis framework (DA) (Studer et al., 2011) can be used to study

\footnotetext{
${ }^{4}$ All the analyses were performed by using the software R version 3.1.2 (R Development Core Team, 2014). The sequence analysis was conducted by using the R packages TraMinerR (Gabadinho et al., 2011) and WeightedCluster (Studer, 2013).
} 
the relationship between sequences and covariates without any prior clustering, freeing us from this implicit assumption. DA translates the more traditional ANOVA framework to sequence analysis. Using DA, we can directly measure the strength of the association using a pseudo- $\mathrm{R}^{2}$ value that can be interpreted as the share of the total variability of the sequences that is accounted for by a covariate. Since we do not simplify the data by any prior clustering, DA leads to a more precise measure of the strength of the association between the trajectories and covariates. Finally, the statistical significance of the association can be attested using permutation tests, which is a major advantage over approaches that rely on cluster analysis.

Analogous to traditional sequence analysis, the input for the discrepancy analysis is a pairwise distance matrix between sequences based on optimal matching or another dissimilarity measure (Abbott \& Forrest, 1986). Following Hollister (2009) and Studer (2012), we use an insertion-deletion cost of 0.5 . The substitution costs were computed with the Gower distance (Gower, 1971; Studer, 2012) considering two properties of the states: union status (single, cohabiting, or married) and having children (yes or no). The statistical significance of the association is estimated using 5000 permutations (Manly, 2007).

First, with DA we can assess whether the sequence discrepancy as an indicator of de-standardization is higher for men or for women (research question 1). The discrepancy can be interpreted as a measure of the variability among the sequences in a given context, e.g. the GDR or the FRG. In a context with less binding social norms, low economic constraints and no regulative interventionist policies, we would expect a high diversity of the sequences because individuals are building their family trajectories independently, resulting in a high discrepancy value, i.e. high de-standardization (FRG). On the contrary, we expect a low discrepancy (low diversity of the sequences) in contexts with strong social norms (or economic/legal constraints) and regulative social policies, since the costs associated with stepping aside from these normative models are high (GDR). Studer and colleagues (2011) proposed a method for testing the homogeneity of the discrepancies based on a generalization of the Levene test. With this test, we can assess whether the discrepancy varies significantly for different groups, i.e. by sub-society and gender. The statistical significance is estimated through permutation tests. Second, DA enables us to measure the association between sequences and different covariates, in our case gender and education. More exactly, we can determine whether the centroid (i.e. "average") sequence is significantly different across subpopulations, in our case for men and women (research question 2). Again, the statistical significance of these differences is assessed through permutation tests. 
As elaborated above, the DA framework is useful to detect any systematic difference between groups of sequences and to measure the magnitude of these differences. However, it does not describe how the groups differ or, in other words, what the qualitative differences are between groups of sequences. To overcome this lack of interpretability, we propose a new tool based on the implicative statistic framework called sequence of typical states, first introduced by Studer (2012 and 2015). The sequence of typical states shows several graphs presenting the typical states for each subpopulation - here men and women -being compared at each time point of the sequences. For instance, state B is considered typical of a subpopulation, e.g. women, if the rule "being a women (instead of a man) implies being in state B" is significant according to the implicative statistics framework. Within this framework, the statistical relevance of a rule is estimated by looking at the number of counterexamples observed in the data. A rule is said to be strongly implicative if we observe a particularly low number of counterexamples.

Strictly speaking, we look at the gap between the observed and the expected number of counterexamples under the independence assumption (Gabadinho et al., 2011; Gras, 1979; Gras et al., 1996; Ritschard, 2005; Suzuki \& Kodratoff, 1998). This gap is computed using adjusted residuals of a contingency table with continuity correction (Agresti, 1990; Ritschard, 2005). The index $I(A \rightarrow B)$ measuring the relevance of the rule "A implies B" reads as follow:

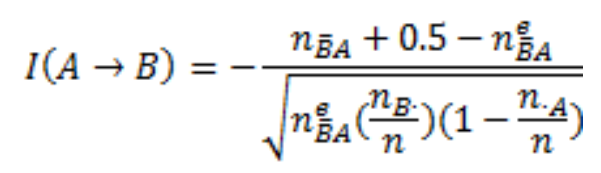

Where $n_{B A \text { is }}$ the observed number of counter-examples, $n_{B A}^{e}$ the expected number

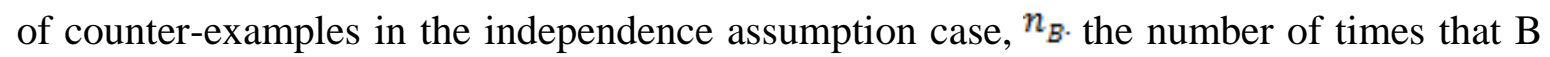
is observed, ${ }^{n} \cdot A$ the number of times that $\mathrm{A}$ is observed and $n$ the total number of cases. In order to improve the readability of the graphs, we use here the opposite of the implicative index that is highly negative for significant rules. The statistical significance of the rule is then computed using a normal distribution (Ritschard, 2005). Note that the strength of the implication rule (i.e., the values on the y axis) is linked to the sample size, since our confidence is larger in big datasets than in smaller ones. Therefore the value of the implication index can only be compared within subsamples but not across sub-samples.

\section{Results}

To give a first descriptive overview of the sequence data Figures 1 and 2 present state distribution plots of family trajectories by respondents' gender and education in the 
two sub-societies. Each plot shows the distribution of individuals across family statuses (yaxis) indicated by different colours at each age represented on the x-axis. A first glance shows differences by gender and education in both West and East Germany. The transition to cohabitation/marriage and to parenthood occurs earlier for women than for men in both sub-societies, with the exception of the highly educated, whose trajectories seem to align to a greater extent for men and women in both East and West Germany. Time spent in cohabitation and marriage without children is shorter for individuals in the GDR. Gender differences in family life courses appear largest among the lower educated in the GDR compared to medium and highly educated individuals. In addition, cohabitation with children is more common among lower educated women than among lower educated men. However, this first descriptive visualization cannot inform us about the statistical significance of these differences between men and women's family trajectories across educational groups.

- Figures $1 \& 2$ about here -

We first turn to research question 1 on differences in the de-standardization of family life courses. Table 2 displays the discrepancy values for each sub-sample considered, i.e. the magnitude of within-group differences in family life courses. Table 3 presents the results from the test on the homogeneity of discrepancy (i.e. the betweengroup differences) to ascertain, whether the de-standardization of family sequences significantly differs for men and women in West Germany compared to East Germany.

- Tables $2 \& 3$ about here -

In line with hypothesis 1 , the results show that family life courses are significantly more de-standardized in the FRG compared to the GDR, and this is equally the case for men and women. According to the Levene test (Table 3), there are no significant gender differences in de-standardization in the West (42.0 for both men and women, Table 2). The same applies to the East, where men and women's average discrepancy is considerably lower (34.5 and 32.2 respectively) compared to the West, but the difference between genders is equally not significant (Table 3). However, in line with previous research, we find higher standardization of family life courses in the GDR with a significantly lower overall discrepancy (34.7 vs. 43.5 in the West, Table 2). These findings are consistent with the argument that the strong state regulation with pro-natalist family policies in East 
Germany homogenized family life courses for both genders compared to the West. Beyond previous descriptive evidence in support of this argument for women (e.g. Elzinga \& Liefbroer, 2007; Fasang, 2014; Kreyenfeld, 2004), the discrepancy analysis enabled us to ascertain the statistical significance of higher de-standardization of family trajectories in the West for both women and men.

- Table 4 about here -

Table 4 presents the results from the discrepancy analysis to assess the degree of gender difference in family trajectories for different educational groups (research question 2). This allows us to test whether the gender differences in family trajectories across educational groups varied for East and West Germany. The pseudo- $\mathrm{R}^{2}$ measures the share of the total variation of the trajectories that is accounted for by the covariate gender for different educational levels for both sub-societies. The pseudo- $\mathrm{R}^{2}$ refers to the comparison of the "average (or central)" sequences in each group. A high pseudo- $\mathrm{R}^{2}$ value means that the "average" sequence in each group, in our case men and women, are very different from each other. The interpretation is therefore different from the Levene test presented in Table 1 , where we compare the variation of the sequences in each group (and not the differences between the centroidal sequences). The pseudo- $\mathrm{R}^{2}$ values are quite low in absolute terms. This is typical for applications on life course sequences and is related to the overall high complexity and large potential variation of life courses, particularly if they are measured in monthly intervals.

Table 4 shows a significant overall association between gender and family trajectories in both sub-societies at a pseudo- $\mathrm{R}^{2}$ of 0.033 for West Germany and 0.038 for East Germany ${ }^{5}$. There is considerable variation of gender differences in family trajectories across educational groups in East and West Germany. For the FRG, gender differences in family life courses are significant across all educational groups: the higher the educational level the weaker the association between gender and family trajectories. In contrast, for the GDR, we find no significant gender differences among highly educated, but stronger gender differences for the medium educated followed by those with low education. Specifically, for the lower educated, gender accounts for $5 \%$ of the variation in the East and $4.1 \%$ in the West. For individuals with a medium level of education the share of variation accounted for by gender is $6.5 \%$ in the East compared to $3.2 \%$ for the West. For

\footnotetext{
${ }^{5}$ The comparison of small differences of pseudo- $\mathrm{R}^{2}$ should be regarded with caution, because we do not explicitly test whether they are significantly different.
} 
the highly educated, gender accounts for only $1.3 \%$ of the variation in family trajectories in the West and is not significant at a very low $0.9 \%$ in the East.

These findings are consistent with a homogenizing impact of educational participation on highly educated men and women's life courses and expectations based on stronger assortative mating among the highly educated (hypotheses 4). In both subsocieties we find the lowest gender differences among the highly educated. The even stronger gender similarity of family life courses in the East is in line with stronger educational homogamy in the East enabled by a more equal distribution of higher education among men and women compared to the West. Possibly, the particularly strong state regulation of access to higher education in the GDR (Blossfeld et al., 2015) further homogenized men and women's family life courses in these high education tracks to a greater extent than institutions of high education in the West.

Importantly, the findings for the GDR do not lend support to the argument that pronatalist and gender-egalitarian policies generated more similar family life courses for men and women for all educational levels (hypothesis 3). Neither are they in line with the educational level hypothesis that would suggest enduring gender differences in family life courses even after the completion of education particularly among the highly educated. Instead, we find no or lower gender differences in family life courses for the highly educated in the GDR and the FRG respectively. This is in line with expectations based on the strong homogamy among the highly educated in the GDR and a homogenizing effect of longer educational participation on highly educated men and women's family life courses.

- Figures 3 and 4 about here -

So far the analyses focused on the degree of gender differences in family life courses using a synthetic discrepancy measure to establish whether statistically significant gender differences exist for different educational groups. We will now explore the qualitative nature of these differences in a more exploratory fashion. In particular, we are interested, whether men and women differ in their family life courses only in terms of a later timing of men's family events or whether there are other pronounced differences between men and women in the two sub-societies.

Figures 3 and 4 display the implicative statistic for sequences of typical states (Studer, 2012). The graph on the left-hand side of each of the four plots in the figures reports the relevance of the rule "Being a man (instead of a woman) implies being in state $x$ at age $t$ ", while the graph on the right-hand side reports the relevance of the rule "Being a 
woman (instead of a man) implies being in state $x$ at age $t$ ". In both case, $x$ is one distinct state of the sequence and $t$ the time points, i.e. months in our case. The horizontal dotted lines show the significance thresholds for confidence at 95\%, 99\%, and 99.9\%. As noted above the strength of the implication rule (i.e., the values on the y-axis) is linked to the sample size, since our confidence is larger in big datasets than in smaller ones. We will therefore only compare the absolute value of the implication within sub-samples and not between sub-samples. When commenting on between sub-samples differences, we will focus only on the significance thresholds indicated by the horizontal dotted lines in the interpretation of the implicative statistic.

For West Germany, plot (a) in Figure 3 shows overall gender differences for all educational groups together, followed by panels (b), (c), and (d) for each educational group separately. We first discuss the overall differences in panel (a) and then continue with the interpretation of the findings for each educational group. The pink line in the left graph of Figure 3 (a) indicates that being a man -instead of a woman - implies being single and childless between ages 18 and 35, where the rule turns insignificant again. This is the expected delay of men's onset of family formation compared to women. Starting from age 28, men have higher implication strength for cohabiting without children compared to women. In contrast, women are overall significantly more likely to be in a childless marriage between ages 18 and 28, and more likely to be married with children until around age 35, as indicated by the light green and dark green lines in the right panel of Figure 3 (a). In addition, compared to men, women have a significantly higher prevalence to be single parents early in the life course between ages 18 and 23 and then again later in life starting around age 33 but not between ages 23 and 33 (purple line on right side of Figure 3 (a)). In fact, by age 40 the only significant difference between men and women's family trajectories in West Germany is the higher implication strength of single parenthood for women, which includes divorced and separated parents in our sequence state definition. This means that all other significant gender differences are only temporary and located largely between ages 18 and 35 .

The basic patterns of gender difference in family trajectories remain similar across educational groups with a few notable timing differences that point to educational participation effects. Whereas low and medium educated women are more likely to be married with children compared to men of their educational group immediately starting from age 18 until around age 33, this difference only sets in for highly educated women at age 25 , consistent with highly educated women postponing motherhood and marriage until the completion of their university education in West Germany. Moreover, single 
parenthood early in the life course between age 18 and 23 is more prevalent for lower educated women compared to lower educated men (Figure 3 (b)). In contrast, highly educated women are significantly more likely than men of their educational group to be a single parent later in life starting from age 33 (Figure 3 (d)). This demonstrates that both the prevalence and the timing of single parenthood among Western women-signified by a higher strength of the implication rule-were education-specific.

For the GDR, the basic patterns are similar with a few notable differences (Figure 4). In line with previous research, gender differences are concentrated in a shorter and earlier demographically dense phase in the life course compared to the FRG. Men are only more likely to be single and childless compared to women until age 28 (compared to 33 in the West, Figure 4 panel (a)). For the lower educated this gender difference turns insignificant already at age 23. In addition lower educated women are more likely to cohabit with children between ages 23 and 35 compared to low educated men. Women with a medium level of education are significantly more likely to be married with children compared to men with medium education until around age 28. In addition, medium educated men are more likely than medium educated women to cohabit with children after age 30. We speculate that these medium educated men (Figure 4(c)) are cohabiting with the younger lower educated women (Figure 4(b)). This could be driving the significant differences between medium and lower educated men and women's family life courses in the GDR (Table 4). Further substantiating findings from the discrepancy analysis (Table 4), we find no significant gender differences in family trajectories for the highly educated based on the implicative statistic for East Germany.

The sequences of typical states based on the implicative statistic highlighted that gender differences in family life courses largely but not exclusively results from men's later family formation, with considerable variation in timing differences for educational groups. However, by age 40, there are very few significant gender differences between men and women's family life courses in East and West Germany. In addition to the later timing of marriage and parenthood for men, we found education-specific gender differences in the prevalence of single parenthood (West) and cohabitation with children (East). Among lower educated women in the East, the implication rule of being a woman and cohabitating with children is stronger starting from age 23 into their mid-thirties. In contrast, the timing and duration of a significantly higher prevalence of single motherhood in the West is education-specific: lower educated women are more likely to be single parents early in the life course. Starting from age 33, highly educated women are more likely to be single parents compared to highly educated men. 
Many of these findings corroborate previous research that separately examined fertility and union formation and dissolution in East and West Germany (see Huinink, 2000 for an overview). In addition to previous research, the sequence implicative statistic enables us to directly compare men and women's family trajectories and to determine where in the process and for which duration in the life course gender differences hold with regard to several family states simultaneously.

\section{Discussion}

In this paper we seek to contribute to the comparative life course literature both substantively and methodologically. Previous research on education and family outcomes prominently fertility, marriage, and cohabitation - has strongly focused on women. We also consider men's family trajectories and directly assess gender differences in longitudinal family life courses until age 40. Because gender-specific effects of education on family events contribute to gender differences in family trajectories, we compared men and women at different educational levels. We used the historically unique case of the German division to underline that the relationship between gender, education, and family life courses is highly context-specific.

In line with previous research, our findings substantiate the fact that both men and women's family life courses were significantly more standardized in the regulative communist GDR compared to the FRG. Findings on gender differences in family life courses for different educational groups are consistent with a strong participation effect for the highly educated and particularly strong homogamy among the highly educated. In both sub-societies gender differences in family life courses were lowest among the highly educated. However, the relationship between gender, education, and family trajectories is highly context-specific. In the FRG there are moderate gender differences in family trajectories for all educational groups, albeit the degree of gender differences diminishes with higher education. In contrast, in the GDR we found sizeable gender differences in family trajectories among the medium and lower educated, but no significant gender differences among the higher educated. This finding is consistent with patterns of assortative mating in the East: educational homogamy was highest among the highly educated and likely contributed to similar family trajectories of highly educated men and women who were partnered with each other. Lower gender differences among the highly educated compared to the medium and lower educated in both sub-societies highlight the homogenizing effect of longer educational participation on men and women's life courses. This homogenizing effect of educational participation apparently overrides the gender- 
specific opportunity cost argument that would predict higher gender differences among the highly educated particularly in the FRG.

The more nuanced analysis of gender differences in the timing of family states based on the implicative statistic further substantiated the profound impact of educational participation for delaying family formation particularly for women in West Germany. Possibly, the strong state regulation of access to higher education in the GDR (Blossfeld et al., 2015) further homogenized men and women's family life courses in this track to a greater extent than institutions of higher education in the West. One reason for this can be seen in the larger proportion of women admitted to higher education in the GDR compared to the FRG, which changed their relative share on the marriage market and thereby affected the dynamics of assortative mating. Notably, our findings are not consistent with expectations on strong educational level effects that would have predicted enduring gender differences in family formation particularly for the highly educated based on gender specific opportunity costs of parenthood.

While the observed gender differences in family trajectories are consistent with expectations based on education-specific assortative mating in East and West Germany, data limitations did not allow us to directly assess educational homogamy for the individuals in our sample. More research is needed to disentangle the role of assortative mating for gender differences in family life courses. It would be particularly interesting to assess the importance of assortative mating for gender differences in family life courses in mediating or moderating the impact of social policies and other institutional effects. Moreover, our specification of family states in the family trajectories did not allow for a more detailed analysis of education-specific gender differences in union dissolution, different types of single parenthood, stepfamily arrangements, or multi-partner fertility. These processes also contribute to variation in the family trajectories that we have observed. However, theorizing and empirically analysing them in more detail was prohibited by low case numbers of the sub-populations who ever experienced these family states in our data. Examining these subpopulations in greater detail will be important to further illuminate gender differences in family life courses.

Finally, in this paper we employed the recently introduced tools of sequence discrepancy analysis and the implicative statistic for analysing sequences of typical states that allowed us to go beyond several weaknesses of commonly applied techniques of sequence analysis. Specifically, the discrepancy analysis enabled us to directly assess the degree to which gender accounts for differences between family sequences. The implicative statistic offered further insights into the nature of gender differences in family 
trajectories by locating precisely the timing and duration when men and women significantly differ in specific family states.

We conclude that promoting a comparative differential life course sociology with small-N country comparisons (Mayer, 2005) is promising to generate new insights into classic questions of life course and social stratification research, including the intersection of gender, education and family life courses. Our analysis contributes to this debate by highlighting education-specific gender differences in family life courses and by presenting new tools to study differences in these processes longitudinally. 


\section{References}

Aassve, A., Billari, F. C., \& Piccarreta, R. (2007). Strings of Adulthood: A Sequence Analysis of Young British Women's Work-Family Trajectories. European Journal of Population / Revue Européenne de Démographie, 23(3-4), 369-388.

Abbott, A. (2005). The Idea of Outcome in U.S. Sociology. In G. Steinmetz (Ed.), The Politics of Method in the Human Sciences (pp. 393-426). Duke University Press.

Abbott, A., \& Forrest, J. (1986). Optimal matching methods for historical sequences. The Journal of Interdisciplinary History, 16(3), 471-494.

Abbott, A., \& Tsay, A. (2000). Sequence analysis and optimal matching methods in sociology. Sociological Methods \& Research, 29, 3-33.

Agresti, A. (1990). Categorical Data Analysis. New York: Wiley.

Aisenbrey, S., Evertsson, M., \& Grunow, D. (2009). Is There a Career Penalty for Mothers' Time Out? A Comparison of Germany, Sweden and the United States, 88, $573-606$.

Balbo, N., Billari, F. C., \& Mills, M. (2013). Fertility in Advanced Societies: A Review of Research: La fécondité dans les sociétés avancées: un examen des recherches. European Journal of Population = Revue Europeenne de Demographie, 29(1), 1-38.

Becker, G. S. (1981). A Treatise on The Family. Cambridge, Mass: Harvard University Press.

Beck-Gernsheim, E. (1988). Die Kinderfrage. Frauen Zwischen Kinderwunsch Und Unabhängigkeit. München: C.H. Beck Verlag.

Bertram, H. (1992). Regionale Disparitäten, soziale Lage und Lebensführungen. In: Hradil, S. (Hg.): Zwischen Bewußtsein und Sein, S. 123-150. Opladen: Leske \& Budrich.

Billari, F. (2001). The Analysis of Early Life Courses: Complex Descriptions of the Transition to Adulthood. Journal of Population Research, 18, 119-142.

Blossfeld, H.P. (ed.) (1995). The new role of women: family formation in modern societies, Boulder Colorado: Westview Press.

Blossfeld, G. J. (2013): What Influences the Rate of Entry into Motherhood of Women 
Enrolled in Full-Time Education? A Difference-in-Differences Analysis of the Effect of the German Unification, in: Studies of Transition States and Societies, 5, 71-85.

Blossfeld, P. N., Blossfeld, G. J., \& Blossfeld, H.-P. (2015). Educational Expansion and Inequalities in Educational Opportunity: Long-Term Changes for East and West Germany. European Sociological Review, 31(2), 144-160.

Blossfeld, H. P., \& Huinink, J. (1991). Human Capital Investments or Norms of Role Transition? How Women's Schooling and Career Affect the Process of Family Formation. The American Journal of Sociology, 97(1), 143-168.

Blossfeld, H.P., Nuthmann, N. (1989). Strukturelle Verainderungen der Jugendphase als KohortenprozefB. Zeitschrift für Padagogik, 35, 845-57.

Blossfeld, H.-P., Roßbach, H.-G., von Maurice, J., Schneider, T., Kiesl, S. K., Schönberger, B., ... others. (2011). Education as a Lifelong Process-The German National Educational Panel Study (NEPS). Age, 74(73), 72.

Blossfeld, H.-P., Timm, A. (eds.) (2003). Who Marries Whom? Educational Systems as Marriage Markets in Modern Societies, Springer Netherlands.

Bras, H., Liefbroer, A. C., \& Elzinga, C. H. (2010). Standardization of pathways to adulthood? An analysis of Dutch cohorts born between 1850 and 1900. Demography, 47(4), 1013-34.

Brückner, H. (2004). Gender Inequality in the Life Course: Social Change and Stability in West Germany 1975-1995. New York: De Gruyter.

Brückner, H., \& Mayer, K. U. (2005). De-Standardization of the Life Course: What it Might Mean? And if it Means Anything, Whether it Actually Took Place? Advances in Life Course Research, 9(04), 27-53.

Brüderl, J. (2004). Die Pluralisierung partnerschaftlicher Lebensformen in Westdeutschland und Europa. Aus Politik Und Zeitgeschichte, 19, 3-10.

Brüderl, J., \& Diekmann, A. (1994). Bildung, Geburtskohorte und Heiratsalter: Eine vergleichende Untersuchung des Heiratsverhaltens in Westdeutschland, Ostdeutschland und den Vereinigten Staaten. Zeitschrift Für Soziologie, 56-73.

Budig, M. J., Misra, J., \& Boeckmann, I. (2012). The Motherhood Penalty in CrossNational Perspective: The Importance of Work-Family Policies and Cultural Attitudes. Social Politics: International Studies in Gender, State \& Society, 19(2), 163-193. 
Carlson, M. J., \& England, P. (Eds.). (2011). Social Class and Changing Families in an Unequal America. Stanford, CA: Stanford University Press.

Carlson, M., McLanahan, S., England, P. (2004).Union formation in fragile families. Demography, 41(2):237-262

Cooke, L. P. (2011). Gender-Class Equality in Political Economies. New York, NY: Routledge.

Cooke, L. P., \& Baxter, J. (2010). "Families" in International Context: Comparing Institutional Effects Across Western Societies. Journal of Marriage and Family, $72(3), 516-536$.

Cook, T. D., \& Furstenberg, F. F. (2002). Explaining aspects of the transition to adulthood in Italy, Sweden, Germany, and the United States: A cross-disciplinary, case synthesis approach. The Annals of the American Academy of Political and Social Science, 580(1), 257-287.

Drasch, K., \& Matthes, B. (2013). Improving retrospective life course data by combining modularized self-reports and event history calendars: Experiences from a large scale survey. Quality and Quantity, 47, 817-838.

Elzinga, C. H., \& Liefbroer, A. C. (2007). De-standardization of Family-Life Trajectories of Young Adults: A Cross-National Comparison Using Sequence Analysis. European Journal of Population / Revue Européenne de Démographie, 23(3-4), $225-250$.

Engelhardt, H., Trappe, H., \& Dronkers, J. (2002). Differences in Family Policy and the Intergenerational Transmission of Divorce : A Comparison between the former East and West Germany. Demographic Research, 6, 295-324.

Esping-Andersen, G. (2009). Incomplete revolution: Adapting welfare states to women's new roles. Cambridge: Polity Press.

Evertsson, M., England, P., Mooi-Reci, I., Hermsen, J., de Bruijn, J., \& Cotter, D. (2009). Is Gender Inequality Greater at Lower or Higher Educational Levels? Common Patterns in the Netherlands, Sweden, and the United States. Social Politics: International Studies in Gender, State \& Society, 16(2), 210-241.

Fasang, A. E. (2014). "New Perspectives on Family Formation: What can we learn from 
Sequence Analysis? In P. Blanchard, F. Bühlmann, \& J.-A. Gauthier (Eds.), Advances in Sequence Analysis: Methods, Theories and Applications. Spinger.

Gabadinho, A., Ritschard, G., Müller, N. S., \& Studer, M. (2011). Analyzing and Visualizing State Sequences in R with TraMineR. Journal of Statistical Software, 40(4), 1-37.

Goldstein, J. R., \& Kreyenfeld, M. (2011). Has East Germany overtaken West Germany? Recent trends in order-specific fertility. Population and Development Review, 37(3), $453-72$.

Goldthorpe, J. H. (2012). Back to class and status: or why a sociological view of social inequality should be reasserted. Revista Espanola de Investigaciones Sociologicas, 137(1), 201-16.

Gower, J. C. (1971). A General Coefficient of Similarity and Some of Its Properties. Biometrics, 27(4), 857-871.

Gras, R. (1979). Contribution à l'étude expérimentale et à l'analyse de certaines acquisitions cognitives et de certains objectifs didactiques. (Thèse d'e.). France: Université de Rennes 1.

Gras, R., Ag Almouloud, S., Bailleul, M., Laher, A., Polo, M., Ratsimba-Rajohn, H., \& Totohasina, A. (1996). L'implication statistique: Nouvelle méthode exploratoire de données. (Recherches.). Grenoble: La pensée sauvage.

Hoem, J. M. (1986). The impact of education on modern family-union initiation. European Journal of Population/Revue Européenne de Démographie, 2(2), 113-133.

Hollister, M. (2009). Is Optimal Matching Suboptimal? Sociological Methods \& Research, $38,235-264$.

Härkönen, J., \& Dronkers, J. (2006). Stability and Change in the Educational Gradient of Divorce. A Comparison of Seventeen Countries. European Sociological Review, $22(5), 501-517$.

Huinink, J. (1995). Education, Work, and Family Patterns of Men: The Case of West Germany, in Blossfeld, H.P. (ed.) "The new role of women: family formation in modern societies", Boulder Colorado: Westview Press.

Huinink, J. (2000). Bildung und Familienentwicklung im Lebensverlauf. Zeitschrift Für 
Erziehungswissenschaft, 3(2), 209-227.

Huinink, J. (2011). New Patterns or No Patterns? Changing Family Development and Family Life in Europe. Studi Interdisciplinari Sulla Famiglia, 49-70.

Huinink, J. \& Mayer, K. U. (1995). Gender, Social Inequality, and Family Formation in West Germany. In: Mason, K. O. \& Jensen, A.-M. (eds.), Gender and Family Change in Industrialized Countries (pp. 168-199). Oxford: Clarendon Press.

Huinink, J., Mayer, K. U., Solga, H., Sørensen, A., \& Trappe, H. (1995). Kollektiv und Eigensinn. Lebensverläufe in der DDR und danach. Berlin: Akademie Verlag.

Keiser, S. (1992). Zusammenfassende Darstellung zentraler Ergebnisse des Familiensurveys-Ost. In H. Bertram (Ed.), Die Familie in den neuen Bundesländern. Stabilität und Wander in der gesellschaftlichen Umbruchssituation (pp. 19-38). Opladen: Leske und Budrich.

Kravdal, Ø., \& Rindfuss, R. R. (2008). Changing Relationships between Education and Fertility: A Study of Women and Men Born 1940 to 1964. American Sociological Review, 73, 854-873.

Kreyenfeld, M. (2002). Time Squeeze, Partner Effect or Self-Selection? An investigation into the positive effect of women's education on second birth risks in West Germany. Demographic Research, 7, 15-48.

Kreyenfeld, M. (2004). Fertility Decisions in the FRG and GDR: An Analysis with Data from the German Fertility and Family Survey. Demographic Research, Special 3, $275-318$.

Kreyenfeld, M. (2010). Uncertainties in female employment careers and the postponement of parenthood in Germany. European Sociological Review, 26(3), 351-366.

Kreyenfeld, M., Zeman, K., Burkimsher, M., \& Jaschinski, I. (2011). Fertility Data for German-speaking Fertility Data in German Speaking Countries: What is the Potential? Where are the Pitfalls? Comparative Population Studies, 36(2-3), 349380.

Mayer, K. U. (2005). Life courses and life chances in a comparative perspective. In: Svallfors, S. (Ed.), Analyzing Inequality: Life Chances and Social Mobility in Comparative Perspective, Palo Alto, CA: Stanford University Press, 17-55. 
Mayer, K. U. (2006). Society of Departure: The German Democratic Republic. In M. Diewald, A. Goedicke, \& K. U. Mayer (Eds.), After the fall of the wall: Life courses in the transformation of East Germany (pp. 29-43). Stanford, CA: Stanford University Press.

Mayer, K. U. (2008). Retrospective Longitudinal Research: The German Life History Study. In S. Menard (Ed.), Handbook of Longitudinal Research: Design, Measurement and Analysis (pp. 85-106). San Diego: Elsevier.

Manly, B. F. J. (2007). Randomization, Bootstrap and Monte Carlo Methods in Biology (Third Edition). New York: Chapman \& Hall.

McLanahan, S., \& Percheski, C. (2008). Family Structure and the Reproduction of Inequalities. Annual Review of Sociology, 34(1), 257-276.

Mickelson, R.A. (2003). Gender, Bourdieu, and the Anomaly of Women's Achievement Redux, Sociology of Education, 76(4), 373-375.

Neugarten, B. L., Moore, J. W., \& Lowe, J. C. (1965). Age Norms, Age Constraints, and Adult Socialization. American Journal of Socioloy, 70(6), 710-717.

Oppenheimer, V. K. (1988). A Theory of Marriage Timing. American Journal of Sociology, 94(3), 563-591.

Orloff, A. S. (2009). Gendering the Comparative Analysis of Welfare States: An Unfinished Agenda. Sociological Theory, 27, 317-343.

Perelli-Harris, B., Sigle-Rushton, W., Kreyenfeld, M., Keizer, R., \& Berghammer, C. (2010). The Educational Gradient of Childbearing within Cohabitation in Europe. Population and Development Review, 36(4), 775-801.

R Development Core Team (2014). R: A language and environment for statistical computing. $\mathrm{R}$ Foundation for Statistical Computing, Vienna, Austria. URL http://www.R-project.org/.

Rindfuss, R. R., Morgan, S. P., \& Swicegood, G. (1988). First births in America: Changes in the timing of parenthood (Vol. 2). Berkeley: University of California Press.

Ritschard, G. (2005). De l'usage de la statistique implicative dans les arbres de classification. In Actes des Troi- sièmes Rencontres Internationale ASI Analyse Statistique Implicative (Vol. 2, pp. 305-314). Palermo: Università degli Studi di 
Palermo.

Rosenfeld, R. A., Trappe, H., \& Gornick, J. C. (2004). Gender and Work in Germany: Before and After Reunification. Annual Review of Sociology, 30(1), 103-124.

Sainsbury, D. (1999). "Gender, policy regimes, and politics." in Gender and Welfare State Regimes, edited by Diane Sainsbury. Oxford: Oxford University Press.

Settersten, R. a, \& Hagestad, G. O. (1996). What's the latest? II. Cultural age deadlines for educational and work transitions. The Gerontologist, 36(2), 602-613.

Settersten, R. a., \& Mayer, K. U. (1997). The Measurement of Age, Age Structuring, and the Life Course. Annual Review of Sociology, 23, 233-261.

Solga, H. (1995). Auf dem Wegin eine klassenlose Gesellschaft? Klassenlagen und Mobilität zwischen Generationen in der DDR. Akademie Verlag, Berlin.

Solga, H. (2006). The Rise of Meritocracy? Class Mobility in East Germany Before and After 1989. In M. Diewald, A. Goedicke, \& K. U. Mayer (Eds.), After the fall of the wall: Life courses in the transformation of East Germany (pp. 140-169). Stanford, CA: Stanford University Press.

Studer, M. (2012). Ètude des inégalités de genre en début de carriere académique à l'aide de méthodes innovatrices d'analyse de données séquentielles. Faculté des sciences économiques et sociales, Thèse $n^{\circ} 777$, Université de Genève.

Studer, M. (2013). WeightedCluster library manual: A practical guide to creating typologies of trajectories in the social sciences with R. LIVES Working Papers 24, NCCR LIVES, Switzerland.

Studer, M. (2015). Comment: On the Use of Globally Interdependent Multiple Sequence Analysis, Sociological Methodology, 45, 81-88.

Studer, M., Ritschard, G., Gabadinho, A., \& Müller, N. S. (2011). Discrepancy Analysis of State Sequences. Sociological Methods \& Research, 40, 471-510.

Suzuki, E., \& Kodratoff, Y. (1998). Discovery of surprising exception rules based on intensity of implication. In Zytkow, J. M. \& Quafafou, M. (eds.), Principles of Data Mining and Knowledge Discovery (pp. 10-18). Springer.

Trappe, H. (1995). Emanzipation oder Zwang? Frauen in der DDR zwischen Beruf, 
Familie und Sozialpolitik. Berlin: Akademie Verlag.

Trappe, H. (1996). Work and family in women's lives in the German Democratic Republic. Work and Occupations, 23(4), 354-377.

Trappe, H., \& Rosenfeld, R. A. (1998). A Comparison of Job-Shifting Patterns in the Former East Germany and the Former West Germany. European Sociological Review, 14(4), 343-368.

Treas, J., \& Widmer, E. D. (2000). Married Women's Employment over the Life Course: Attitudes in Cross-national Perspective. Social Forces, 78(4), 1409-1436.

Wagner, M. (1997). Scheidung in Ost- und Westdeutschland. Zum Verhältnis von Ehestabilität und Sozialstruktur seit den 30er Jahren. Frankfurt/Main: Campus Verlag.

Widmer, E. D., \& Ritschard, G. (2009). The de-standardization of the life course: Are men and women equal? Advances in Life Course Research, 14, 28-39.

Wirth, H. (2000). Bildung, Klassenlage und Partnerwahl. Opladen: Leske und Budrich. 


\section{Tables}

Table 1: Distribution of the highest educational degree obtained by gender in West and East Germany, birth cohorts 1944-1955. Source: NEPS data.

\begin{tabular}{|c|c|c|c|c|c|c|}
\hline & \multicolumn{3}{|c|}{ West } & \multicolumn{3}{|c|}{ East } \\
\hline & Men & Women & Tot. & Men & Women & Tot. \\
\hline \multicolumn{7}{|c|}{ Education } \\
\hline Low & 43.7 & 46.5 & 45.1 & 21.3 & 16.9 & 19.2 \\
\hline Medium & 26.9 & 35.9 & 31.2 & 50.9 & 59.9 & 55.3 \\
\hline High & 29.4 & 17.6 & 23.7 & 27.8 & 23.2 & 25.5 \\
\hline Total & 100 & 100 & 100 & 100 & 100.0 & 100.0 \\
\hline$N$. & 915 & 863 & 1.778 & 216 & 207 & 423 \\
\hline
\end{tabular}


Table 2: Within-group discrepancy analysis of family trajectories from age 18 to 40, birth cohorts 1944-1955. Source: NEPS data.

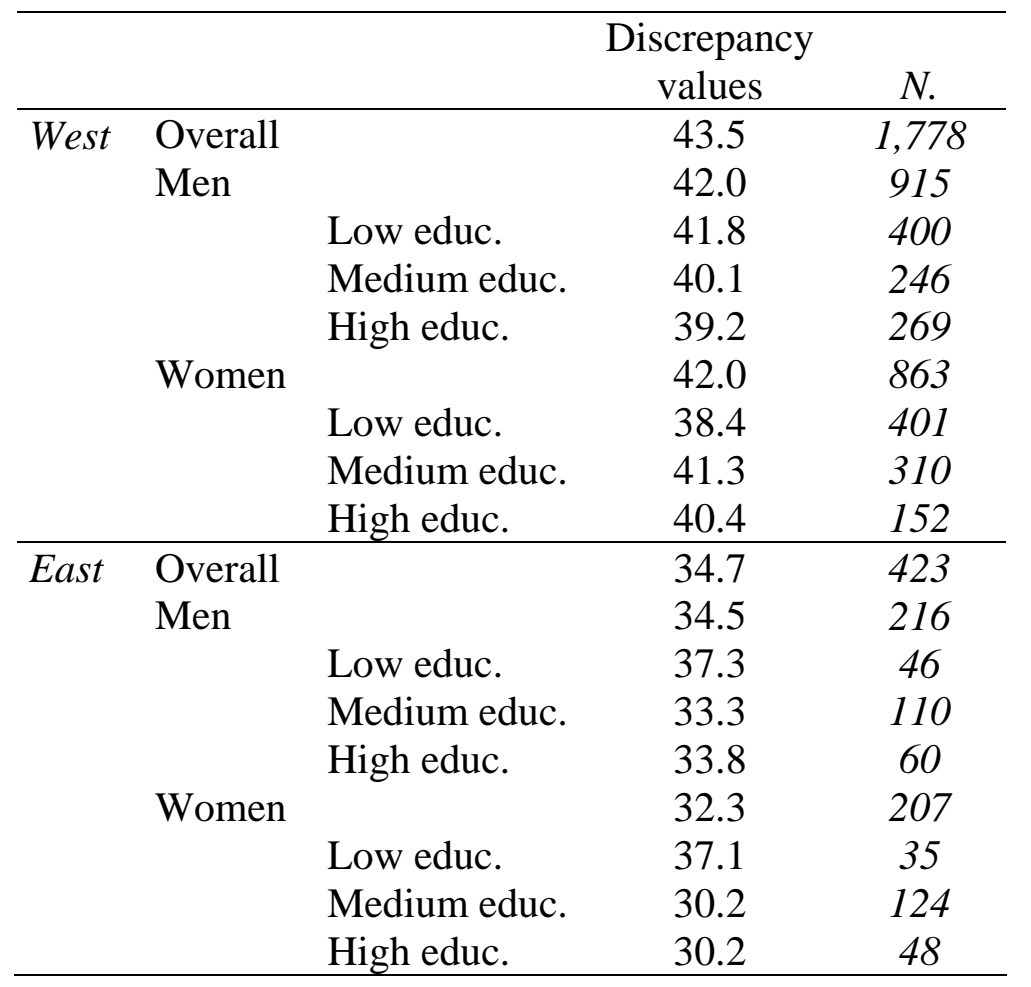

Table 3: Between-group discrepancy analysis of family trajectories from age 18 to 40, births cohort 1944-1955. P-value significance of the Levene's test: n.s. $=$ not significant, $*=0.05, * *=0.01$, based on 5000 permutations (Studer et al., 2011). Source: NEPS data.

\begin{tabular}{|c|c|c|c|}
\hline & & Significance & $N$. \\
\hline \multicolumn{4}{|l|}{ Men vs. Women } \\
\hline \multirow[t]{3}{*}{ Overall } & & n.s. & 2,201 \\
\hline & West & n.s. & 1.778 \\
\hline & East & n.s & 423 \\
\hline \multicolumn{4}{|c|}{ Low educ. } \\
\hline & West & $*$ & 801 \\
\hline & East & n.s. & 81 \\
\hline \multicolumn{4}{|c|}{ Medium educ. } \\
\hline & West & n.s. & 556 \\
\hline & East & n.s. & 234 \\
\hline \multicolumn{4}{|c|}{ High educ. } \\
\hline & West & n.s. & 421 \\
\hline & East & n.s & 108 \\
\hline \multicolumn{4}{|l|}{ West vs. East } \\
\hline Overall & & $* *$ & 2,201 \\
\hline Men & & $* *$ & 1,131 \\
\hline Women & & $* *$ & 1,070 \\
\hline
\end{tabular}


Table 4: Pseudo- $\mathrm{R}^{2}$ values for gender differences from the between-group discrepancy analysis of family trajectories from age 18 to 40 by education, birth cohort 1944-1955. P-value significance: $+=0.10, *=0.05, * *=0.01$, based on 5000 permutations. Source: NEPS data.

\begin{tabular}{rcc}
\hline Men vs. Women & Pseudo-R2 & $N$. \\
\hline Overall & & \\
West & $0.033^{* *}$ & 1,778 \\
East & $0.038^{* *}$ & 423 \\
Wow educ. & & \\
Eest & $0.041^{* *}$ & 801 \\
East & $0.050^{* *}$ & 81 \\
West & $0.032^{* *}$ & 556 \\
East & $0.065^{* *}$ & 234 \\
Migh educ. & & \\
West & $0.013^{* *}$ & 421 \\
East & 0.009 & 108 \\
\hline
\end{tabular}




\section{Figures}

Figure 1: State distribution plots of family formation by gender and education in West Germany, birth cohorts 1944-1955. Source: NEPS data.

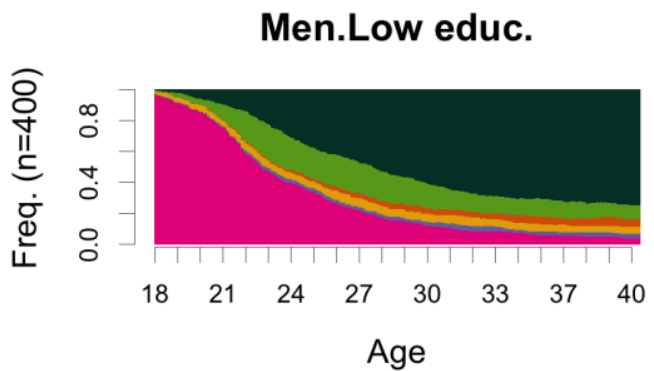

Men.Medium educ.

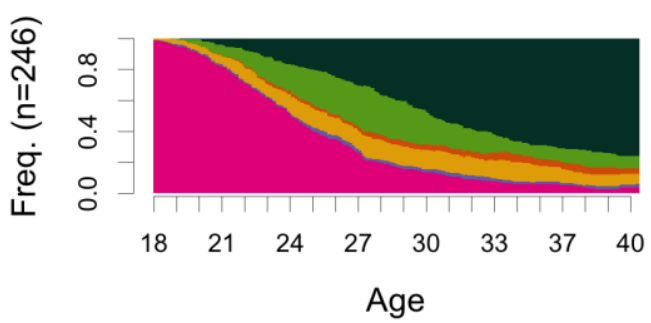

Men.High educ.

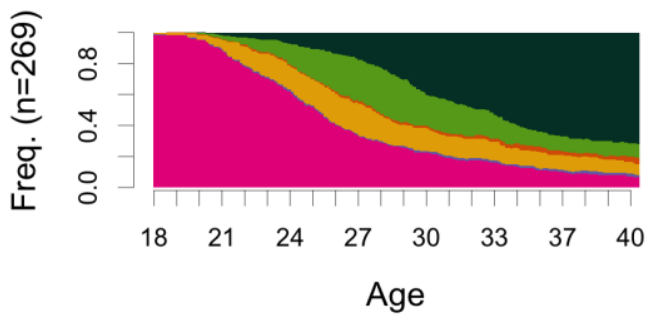

Women.Low educ.

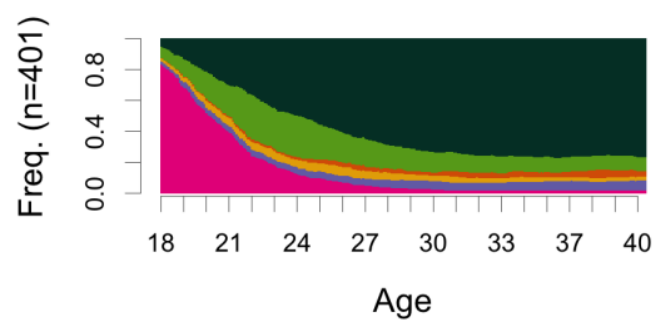

Women.Medium educ.

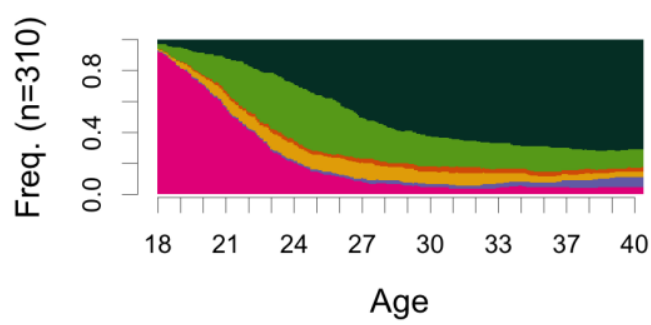

Women.High educ.

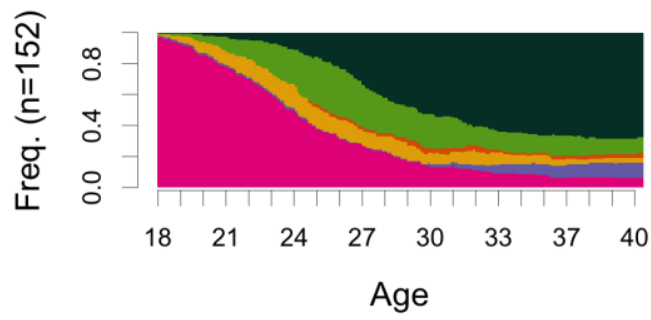

- single no kids

single $1+$ kids

cohabiting no kids

married no kids

- cohabiting 1+ kids

married 1+ kids 
Figure 2: State distribution plots of family formation by gender and education in East Germany, birth cohort 1944-1955. Source: NEPS data.
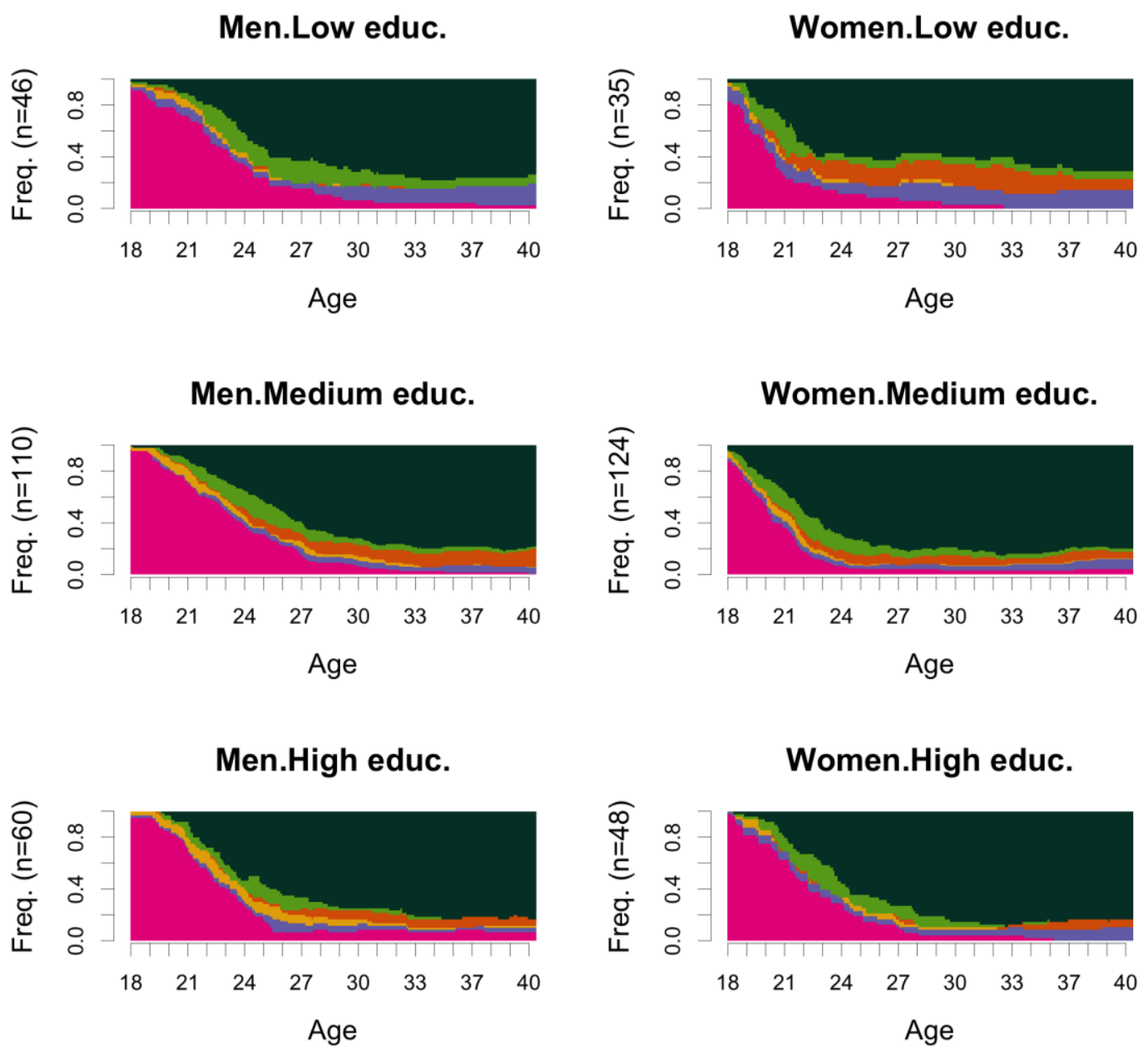

single no kids $\square \begin{aligned} & \text { cohabiting no kids } \square \text { married no kids } \\ & \text { single } 1+\text { kids }\end{aligned}$ cohabiting 1+kids $\square$ married 1+kids 

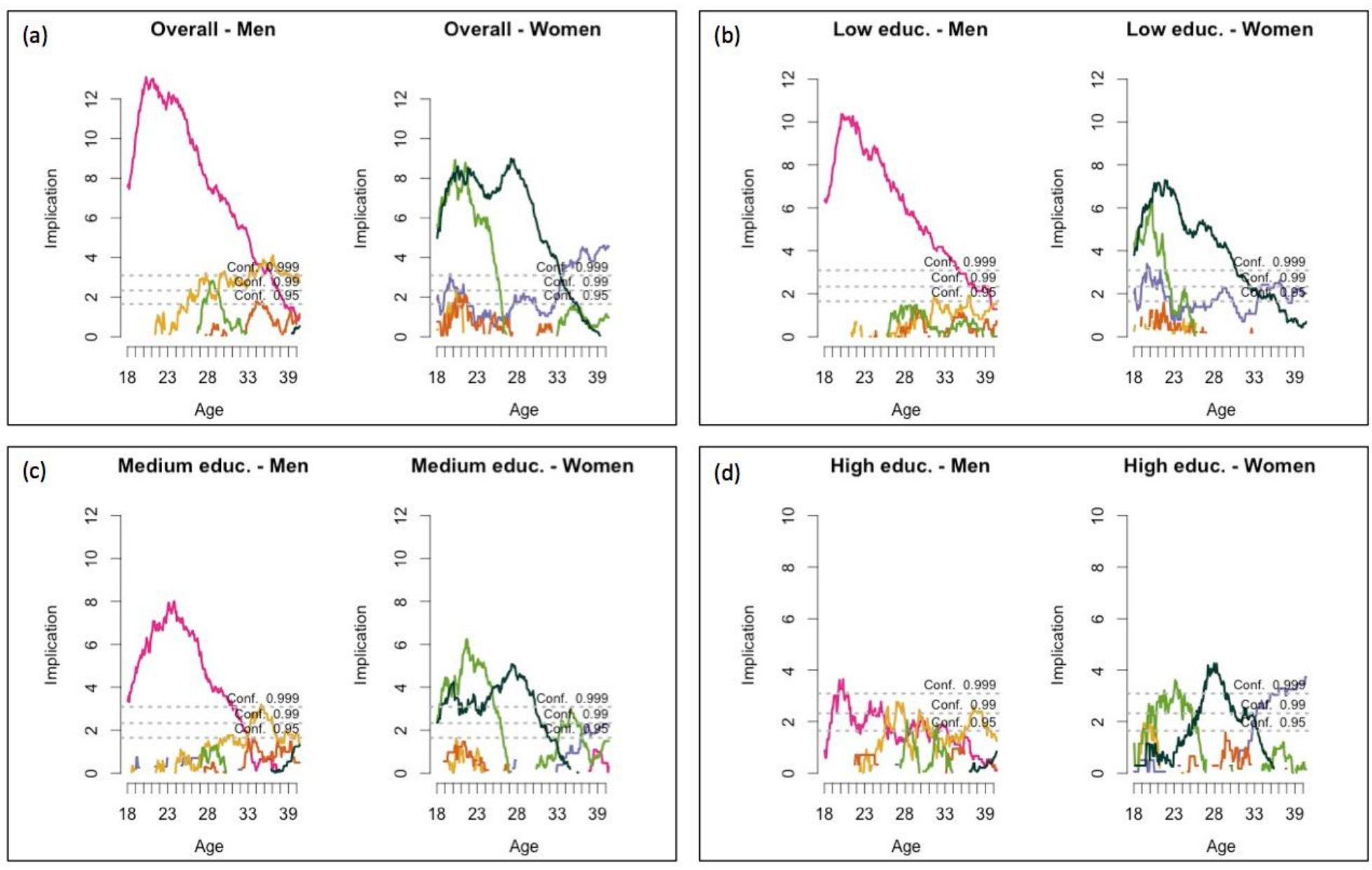

$$
\begin{aligned}
& \text { single no kids }=\begin{array}{l}
\text { cohabiting no kids }=\text { married no kids } \\
\text { single } 1+\text { kids } \\
\text { cohabiting } 1+\text { kids }
\end{array} \text { married } 1+\text { kids }
\end{aligned}
$$

Figure 3 Implicative statistic applied to sequences of typical states analysis: comparison between men and women in West Germany by education, birth cohort 1944-1955. Sample size for each sub-group can be found in Table 2. Source: NEPS data. 

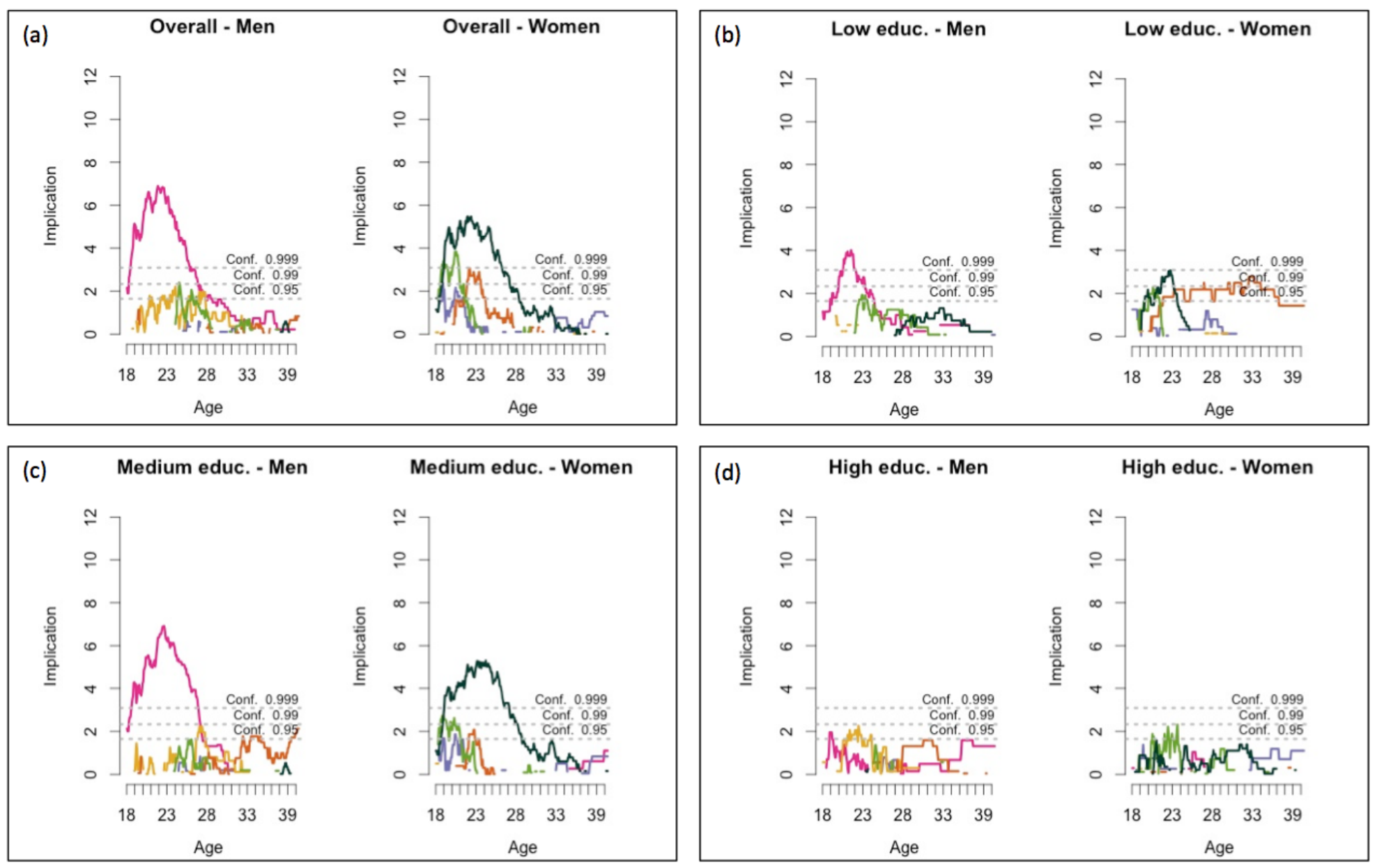

High educ. - Women
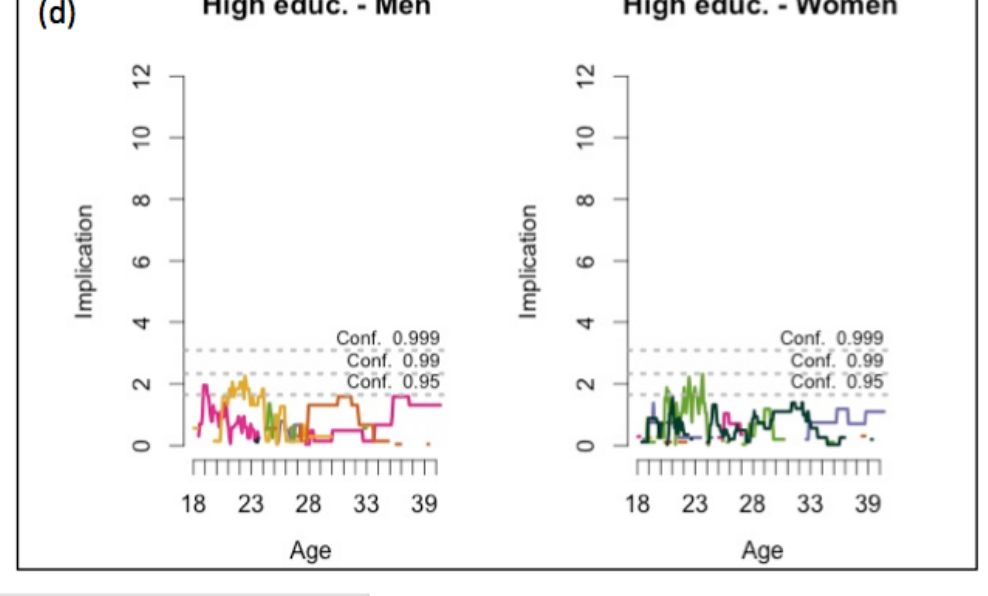

$$
\begin{aligned}
& \text { angle no kids } \\
& \text { single } 1+\text { kids }
\end{aligned}
$$

Figure 4 Implicative statistic applied to sequences of typical states analysis: comparison between men and women in East Germany by education, birth cohort 1944-1955. Sample size for each sub-group can be found in Table 2. Source: NEPS data. 